\title{
Students' Perceptions Towards the Benefits and Drawbacks of EMI
}

\section{Classes}

\author{
Yen H. Phuong ${ }^{1} \&$ Thong T. Nguyen ${ }^{1}$ \\ ${ }^{1}$ School of Foreign Languages, Can Tho University, Vietnam \\ Correspondence: Yen H. Phuong, School of Foreign Languages, Can Tho University, Vietnam.
}

Received: March 1, 2019 Accepted: April 13, 2019 Online Published: April 16, 2019

doi: 10.5539/elt.v12n5p88 URL: https://doi.org/10.5539/elt.v12n5p88

\begin{abstract}
Globalization and internationalization have fostered the development of English as a medium of instruction (EMI). EMI is gaining its popularity all over the world. In line with this tendency, various universities in Vietnam introduce EMI to its undergraduate programs in forms of advanced or high-quality training programs. However, little research has been conducted to discover the benefits as well as drawbacks of these EMI programs, especially in context where English is not a second language nor popularly used outside the classroom as in Vietnam. The purpose of this study was therefore conducted to explore the issue in a university in Vietnam. A group of 136 sophomores majoring in International Business and Information Technology participated in this study. A questionnaire was administered to them to obtain quantitative data. Six students were selected randomly to take part in individual interviews to obtain qualitative data. Results indicated that students perceived four clusters of benefits and drawbacks that EMI classrooms provide.
\end{abstract}

Keywords: EMI, benefits, drawbacks, undergraduate students

\section{Introduction}

English has become an international means of communication (Crystal, 2003; Wright, 2004; Tamtam, Gallagher, Olabi, \& Nasher, 2012). Thus, it is gaining its popularity worldwide as means of instruction in higher education all over the world. In a comparative study conducted by Tamtam et al. (2012) to investigate the implementation of English as a medium of instruction (EMI) in higher education systems in Europe, Asia and Africa, the researchers claim that compared to Asian and African nations, non-English-speaking European countries witnessed greater success in implementing EMI. Specifically, in Europe, numerous universities consider EMI very important (Tamtam et al., 2012) for reasons including internationalization, student exchanges, staff mobility, graduate employability and international student market (Ammon \& McConnell, 2002).

With regards to Asian countries, EMI approach has been practiced; however, some nations in this continent are against the implementation of EMI. Saudi Arabia, for example, regards EMI as a cultural threat that may result in a "cultural catastrophe" (Al-Jarf, 2004; Al-Sultan, 2009; Tamtam et al., 2012). Thus, instead of resorting to EMI, developed countries in Asia choose to launch translation programs which are supposed to make their indigenous languages richer (Rundall \& Hernandez, 1986). Opposition from the representatives of the nations and a lack of interest among native learners are two of many other challenges leading to ineffective implementation of EMI in Asia.

Meanwhile, Vietnam's neighboring country - China - has been promoting EMI in its top universities for the past decade (Lei \& Hu, 2014). At the beginning of this century, the Ministry of Education (2001) commenced broadcasting EMI as crucial guidelines for enhancing the quality of undergraduate education. The Director of the MOE Higher Education Department stated that "the English proficiency of faculty and students is an important indicator of a university's competitiveness and quality of education" (Zhang, 2002). Most Chinese universities have applied EMI programs in order to 'bring higher education in China up to the level of developed countries' and enforce 'China's competitiveness in the global arena' (Lei \& Hu, 2014). These universities have adopted EMI so that they can 'acquire prestige, raise their national and international rankings, attract more students and improve their graduates' competitiveness in the job market' (Hu, 2007). It can be concluded that EMI has grown rapidly in China over the past decade (Hu, 2007; Pan, 2007).

In Vietnam, EMI is considered an innovation because it is expanded to learners from all educational levels, 
particularly to students in universities and higher-education institutions. Multiple EMI programs have been introduced to most of the levels of education in Vietnam, from public to private sectors. According to a report presented by Dearden (2014), by sector and level, only public primary schools did not adopt EMI. This suggests that EMI has widely spread the country.

As pointed out by Gill (2004), tertiary education is the "major means of meeting human resource needs". Thus, EMI at Higher Education Institutions (HEIs) in Vietnam needs to be particularly considered. The university being investigated in the current study is one of the leading higher education institutions in the Mekong Delta of Vietnam. Training, conducting scientific research and transferring technology are its main missions. There are approximately 2000 staff members including teaching and supporting staff. The university recruits thousands of students from various high schools throughout the country and many students on internship programs from the United States, Belgium, Japan, Thailand and so on. The university currently has 98 undergraduate programs, including 2 advanced programs and 3 high-quality training programs. These advanced and high quality training programs are considered as a response to the implementation of EMI in the university with the latters being initiated at the university for three years. As compared to the formers, these high quality programs received no support from foreign partner institutions. Therefore, it is worth investigating the benefits and drawbacks that students perceived from these two EMI programs to propose suggestions on how to optimize them. Few studies have been conducted to explore the issue and the current study was implemented to fill such a gap. It seeks to answer the following research question:

\section{What are the benefits and drawbacks of EMI as perceived by students?}

\section{Literature Review}

\subsection{English as a Medium of Instruction}

It is 'not straightforward' to answer the question of what EMI is (Vu \& Burns, 2014). Thus, there are several different views on the definition of EMI. However, those ones appear to share some common things. Dearden (2014) defines EMI as the use of English to teach specialized subjects in nations where English is not the first language of the majority of the population. Likewise, Madhavan and McDonald (2014) believe that EMI is the teaching of a subject using English language where English is not the official language. They add that EMI has no clear language learning aims.

In terms of the percentage of the curriculum instructed in students' mother tongue, some other researchers define EMI in a slightly different way. According to Swain and Johnson (1997), there are two versions of EMI: full EMI and partial EMI. The former is a form of bilingual education in which native language is not allowed to use in curriculum, whereas the latter is a bilingual program in which less than $50 \%$ of the curriculum taught in English.

In some other studies, EMI is seen as a teaching and learning strategy that involves "focus on non-language subject-matter, and focus on the language, in terms of both communication and cognition" (Marsh \& Laitinen, 2005; Tamtam et al., 2012).

In this study, EMI refers to an innovative approach in which English is utilized as a medium of instruction by lecturers to teach academic subjects to their students.

\subsection{Benefits and Drawbacks that EMI Offers Students}

\subsubsection{Benefits}

EMI is proved to offer four groups of benefits namely cognitive advantages, resource availability, more exposure to English and more chances to acquire it and the increased employability chances of students.

Regarding cognitive advantages, some research has demonstrated that bilingualism correlates with divergent thinking. Bilingual children are more fluent and flexible than their monolingual counterparts (Baker \& Jone, 1998). Senapati, Patnaik and Dash's (2012) study revealed that EMI pupils are "more out-going, active, emotionally mature, assertive, competitive, conscientious and independent-minded" than Odia-medium ones. In addition, raising metalinguistic awareness is another cognitive advantage of bilingualism in general and EMI in particular (Bialystock, 1987).

In term of resource availability, EMI provides students with access to materials which are not available in their mother tongue (Alhamami, 2015; Başibek, Dolmacı, Cengiz, Bür, Dilek, \& Kara, 2014; Probyn, 2005; Zare-ee \& Gholami, 2013). Science textbooks and other reliable materials are usually published in English. Therefore, to access these resources, students are required to be proficient in English, making the role of EMI even more significant. 
In addition, EMI is claimed to provide more exposure to English and more chances to acquire it. EMI is believed to enhance students' English proficiency (Galloway, 2017). In a large scale study undertaken by Belhiah and Elhami (2015) with 500 students from 6 universities in the Arabian Gulf, it is reported that they had made considerable progress in listening, speaking, writing and reading skills. Similarly, another study by Tatzl (2011) demonstrated that students' linguistic skills, including academic or specialized vocabulary size, were significantly enhanced. Also, EMI is also a tool that student could take advantage of in order to compensate their lack of command of English.

Last but not least, EMI increases employability chances of students. Since there is an increasing number of foreign companies in many countries throughout the world, being bilingual may be the key to career prospects. Tamtam et al. (2012, p. 1423) propose that bilingualism is the root of "career and studying opportunities". Students will probably be offered employment or promotion prospects if they are proficient English users.

\subsubsection{Drawbacks}

Despite various benefits described above, EMI also brings students different challenges in comprehending lectures and textbook/course materials; taking tests and exams, and taking part in classroom discussion.

First, difficulties in comprehending lectures are one of the most common issues raised by EMI students whose native language is not English. These students are dissatisfied with the knowledge they have gained when English is used as a medium of instruction (Chang, 2010; Huang, 2009, 2012; Tatzl, 2011). Incompetence in listening comprehension skills among EMI students make students fail to catch important points delivered in the lectures. Furthermore, students who are incompetent in speaking skills cannot clear up their confusion by means of asking questions. Failing to read effectively can also result in the loss of details given by lecturers (Ibrahim, 2001). Even in top universities in China, professors or lecturers frequently have to summarize the learning content previously delivered in English language in order to help students comprehend the lectures better (Tong \& Shi, 2012).

With regards to challenges in comprehending textbooks/ course materials, Al-Bakri (2013) reports that reading textbooks written in English is one of the greatest challenges to students. A lack of vocabulary and academic knowledge may be the cause of this. To comprehend the learning content, they have to look up new words or vocabulary items using a dictionary and then translate the text into their native language. This is time-consuming and ineffective. Additionally, in another research by Keuk and Tith (2013), most students report that unfamiliar words and terminology seriously prevent them from digesting the information provided in their textbooks. Limited vocabulary and slow reading speed were two of the many reasons leading to the inability to understand the learning content (Chang, 2010). "The level of difficulty of the English language used in the materials" is also one of the major causes of low level of reading comprehension (Le, 2015, p. 14).

Taking tests and exams is another important challenge to EMI students. Al-Bakri's (2013) research also reveals that most of the participants have difficulty in comprehending exam questions. Similar findings can also be found in a study by Sivaramana, Al Balushib and Rao (2014). EMI students in these studies mentioned that they were not able to understand the questions thoroughly, or they misunderstood the questions. As a result, they cannot answer the questions even if they gain sufficient knowledge in their mother tongue. Moreover, those who are able to understand the questions cannot answer them in detail due to the lack of English language proficiency (Le, 2015). Being unsure of how academic words and terms are spelt makes students hesitant to express their ideas academically, which in turn results in low grades.

Students also encounter challenges in taking part in classroom discussions. Many EMI students have reported that they encounter challenges in participating in classroom discussions (Doiz, Lasagabaster, \& Sierra, 2012; Flowerdew \& Miller, 1992). Students with low English competence find it hard to express themselves (Ibrahim, 2001). Consequently, they are unwilling to pose questions. Moreover, they are discouraged to create and maintain interpersonal relationship with their peers and lecturers. In such circumstances, a classroom is for studying academic subjects and developing cognitive skills, not for developing social skills, which restrains social functions of the language (Ibrahim, 2001). Similarly, it is shown that students cannot maintain a conversation over a long period of time (Sivaramana et al., 2014). Low language-ability students face the problem of low self-esteem, which prevents them from taking part in class-based communication (Al-Bakri, 2013). EMI students also admitted that they were shy and hesitant to make mistakes (Kagwesag, 2012).

\section{Research Methods}

\subsection{The Context and Participants}

The implementation of EMI is an advancement in the Vietnam policy. According to Vietnam Government (2008), 
"educational institutions are encouraged to develop and implement bilingual programs". As a result, numerous EMI programs have been established not only in public universities but also in private ones since 2008 (Vu \& Burns, 2014. According to Nguyen, Walkinshaw and Pham (2017), EMI programs offered at HEIs in Vietnam can be categorized into foreign programs and domestic programs. A foreign program, called an advanced program, is the implementation of EMI based on the cooperation between a country and foreign institutions to deliver academic resources and activities, including curricula, materials and assessment (Nguyen, 2009). Differently, domestic programs are locally developed with reference to overseas programs (Nguyen et al., 2017) and are named high quality programs.

The participants of this study are EMI sophomores following the high quality programs of International Business and Information Technology. All students of the two programs received a letter inviting them to participate in the study. Among 142 students, a total of 136 students (61 males and 75 females) agreed to participate in the survey. A consent form was sent to them to sign before they answered the items in the questionnaire. There were 59 students majoring in International Business (43.4\%) and 77 students studying Information Technology (56.6\%), with their age ranging from 19 to 23. Most of the participants rated their English proficiency at intermediate level (76 students). The number of students assuming their English proficiency is elementary was 44. Only 9 and 7 students believed their English was at beginner and advanced levels, respectively.

\subsection{Questionnaire}

A 5-point Likert Scales questionnaire was designed basing on the advantages and disadvantages of EMI reviewed in the literature. The questionnaire was sent to three senior researchers in the field to comment on the clarity of each item. After vocabulary revisions were conducted, the questionnaire was then piloted with 30 students of a similar cohort with high reliability (36 items; $\alpha=.89$ ). The questionnaire was later administered to the participants.

In detail, the questionnaire consists of three sections. Section 1 was designed to collect the participants' personal information, namely gender, age, email address, major, English proficiency and present certificate of English. Section 2 comprises of 19 closed-ended items which are categorized into 4 clusters, namely cognitive advantages, resource availability, chances to practice and acquire English and employability/ job prospects. Section 3 investigates the disadvantages the students experience when EMI lessons are delivered. Like Section 2, this section also consists of 19 closed-ended items and is also divided into 4 clusters (difficulties in comprehending the lectures, difficulties in comprehending the textbooks or course materials, difficulties in taking tests and exams and difficulties in participating in classroom discussions, respectively). For each item in Section 2 and 3, the participants were asked to put a tick in the column which best corresponds to their case. The data assembled from the questionnaire was then analyzed using Statistical Package for the Social Sciences (SPSS) version 20. The outcomes from the questionnaire were used as a framework for further investigation in the interview. A reliability test revealed that the questionnaire is highly reliable (36 items; $\alpha=.92)$.

\subsection{Interviews}

The interviewees were 6 students who were selected randomly from 136 participants (3 from International Business and 3 from Information Technology). Each interviewee answered four questions posed by the researcher. These ones primarily focuses on the benefits and drawbacks of EMI lessons. Additionally, the interviewees were free to discuss any aspects of EMI programs.

\section{Results}

\subsection{Benefits of EMI Lessons as Perceived by Students}

With regard to cognitive benefits, the mean value of items is 3.50, meaning that EMI classrooms do bring cognitive benefits.

Table 1. Cognitive advantages as perceived by EMI students

\begin{tabular}{llll}
\hline Item & $\begin{array}{l}\text { Agree } \\
(\%)\end{array}$ & $\begin{array}{l}\text { Disagree } \\
(\%)\end{array}$ & $\begin{array}{l}\text { Neutral } \\
(\%)\end{array}$ \\
\hline Studying in an EMI class makes me more active and competitive. & 55.9 & 11.7 & 32.4 \\
Studying in an EMI class correlates with divergent thinking. & 52.2 & 5.9 & 41.9 \\
Studying in an EMI class makes me more out-going. & 51.4 & 13.3 & 35.3 \\
\hline
\end{tabular}


Table 1 reveals that slightly more than half of the respondents believed that studying in an EMI class (1) makes them more active, competitive and out-going and (2) correlates with divergent thinking, with $55.9 \%$ and $52.2 \%$ respectively. The statement which received both the lowest percentage of agreement and the highest percentage of disagreement out of the three statements is "Studying in an EMI class makes me more out-going", with 51.4\% and $13.3 \%$, respectively. On the whole, fractionally more than half of the students assumed that EMI classrooms offer them cognitive advantages.

In terms of resource availability, the mean value is 3.64, which suggests that the students expressed positive attitudes towards EMI lessons in this respect.

Table 2. Resource availability of EMI classes

\begin{tabular}{llll}
\hline Item & $\begin{array}{l}\text { Agree } \\
(\%)\end{array}$ & $\begin{array}{l}\text { Disagree } \\
(\%)\end{array}$ & $\begin{array}{l}\text { Neutral } \\
\text { (\%) }\end{array}$ \\
\hline $\begin{array}{l}\text { Attending an EMI class enables me to find sources of information written } \\
\text { in English. }\end{array}$ & 75.7 & 10.3 & 14 \\
$\begin{array}{l}\text { Attending an EMI class enables me to find materials for my major. } \\
\begin{array}{l}\text { Being proficient in English helps me to make smart choices on which } \\
\text { materials to read. }\end{array}\end{array}$ & 70.6 & 12.5 & 16.9 \\
$\begin{array}{l}\text { Due to the ability to find materials written in English, I can become } \\
\text { involved in research. }\end{array}$ & 39 & 14.7 & 49 \\
\hline
\end{tabular}

More specifically, Table 2 shows that slightly more than three-quarters of the respondents asserted that EMI lessons enable them to find sources of information written in English. Similarly, the statement "Attending an EMI class enables me to find materials for my major" received the second most agreement, with $70.6 \%$ of the participants. In addition, approximately half of the students under survey believed that being proficient in English helps them to make smart choices on materials. However, a relatively small percentage of the students (39\%) considered the ability to find materials written in English as a tool for being involved in scientific research. Furthermore, $46.3 \%$ of them had no idea on this item, meaning that they hesitate to decide on whether the ability to find materials written in English is useful enough to be involved in research. In general, data revealed that most students strongly believe that they really benefit from EMI classrooms in terms of the ability to find information and materials written in English. Nevertheless, there was a sign of hesitation among them in seeing the ability to find materials written in English as a useful tool to conduct research.

Regarding the third benefit, the students acknowledged the effectiveness of EMI programs in providing them with a favorable environment to learn English, with the mean value being 3.63. However, there were significant differences between the skills developed in an EMI environment (see Table 3).

Table 3. Learning opportunities in EMI classes

\begin{tabular}{lllc}
\hline \multicolumn{1}{c}{ Item } & $\begin{array}{c}\text { Agree } \\
(\%)\end{array}$ & $\begin{array}{c}\text { Disagree } \\
(\%)\end{array}$ & $\begin{array}{c}\text { Neutral } \\
(\%)\end{array}$ \\
\hline $\begin{array}{l}\text { My general and academic vocabulary size is enhanced during EMI } \\
\text { classes. }\end{array}$ & 86.8 & 1.5 & 11.8 \\
Studying in an EMI class enhances my listening, reading, speaking and & 75 & 5.1 & 19.9 \\
writing skills. & 70.6 & 8.1 & 21.3 \\
Studying in an EMI class enhances my subject matter knowledge. & 68.4 & 1.5 & 30.1 \\
I can listen well during the lectures. & 55.1 & 5.1 & 39.7 \\
I can read and understand texts in my subject area. & 51.5 & 16.9 & 31.6 \\
Studying in an EMI class compensates my lack of command of English. & 46.3 & 8.8 & 44.9 \\
I can write in English using academic vocabulary. & 38.2 & 8.8 & 52.9 \\
I can get on well with people from English-speaking countries. & 36.7 & 9.6 & 53.7 \\
I am confident in using English in classroom discussions. & & & \multicolumn{2}{|c}{} \\
\hline
\end{tabular}


As presented in the above table, an large proportion of the participants (86.8\%) agreed that EMI lessons enhances their general and academic vocabulary size. Importantly, 75\% of them believed that EMI lessons sharpens their four English skills, namely listening, reading, speaking and writing. Similarly, a fairly high percentage, namely $70.6 \%$, went to the statement "Studying in an EMI class enhances my subject matter knowledge". These can be considered as positive points that EMI lessons bring to the students.

However, there were significant differences between the development of English skills as perceived by the students. In detail, less than $40 \%$ of the respondents thought that they (1) are confident in using English in classroom discussions and (2) can get on well with people from English-speaking countries, with $36.7 \%$ and $38.2 \%$, respectively. Similarly, only $46.3 \%$ perceived they can write in English using academic vocabulary. These figures suggest that not so many are confident with their writing and speaking skills. In other words, these skills have not been developed much in EMI classrooms. In contrast, listening and reading skills appear to be sharpened much more. More specifically, $68.4 \%$ of the students agreed that they can listen well during the lectures. Additionally, the statement "I can read and understand texts in my subject area" received the agreement from $55.1 \%$ of the participants. Just $51.5 \%$ believed that studying in an EMI class compensates their lack of command of English, meaning that EMI lessons do not play an important role in filling the gaps in knowledge of English among the students.

The benefits of job opportunities that EMI programs can offer received the highest agreement with the mean value being 4.09 .

Table 4. Future job opportunities provided by EMI programs

\begin{tabular}{llll}
\hline Item & $\begin{array}{l}\text { Agree } \\
(\%)\end{array}$ & $\begin{array}{l}\text { Disagree } \\
(\%)\end{array}$ & $\begin{array}{l}\text { Neutral } \\
(\%)\end{array}$ \\
\hline $\begin{array}{l}\text { Studying in an EMI class increases my chance for job search or further } \\
\text { studies upon graduation elsewhere. }\end{array}$ & 87.5 & 3.7 & 8.8 \\
Studying in an EMI class promises me a well-paid job in the future. & 75 & 3.7 & 21.3 \\
Studying in an EMI class increases promotion prospects. & 73.5 & 5.9 & 20.6 \\
\hline
\end{tabular}

As can be seen from Table 4, all of the items received great percentages of agreement from the participants. Specifically, the highest proportion of the students, namely $87.5 \%$, perceived that an EMI class increases their chances in job markets and further studies. A majority of the students also believed that studying in an EMI class (1) promises them well-paid jobs in the future and (2) increases promotion prospects, with $75 \%$ and $73.5 \%$, respectively. These outcomes reveal that EMI students have a strong belief in that an EMI environment offers them great job opportunities in the future.

Qualitative data from the interviews provide additional details to the ideas that students provide via the questionnaire responses. Regarding cognitive advantages of EMI classes, some of the interviewees indirectly mentioned cognitive advantages. Their opinions are illustrated as follows:

[...] The greatest benefit is that this program offers courses on problem solving skills and communication skills in addition to specialized subjects taught in English. Therefore, I think the most considerable advantage is that I can solve difficult real-life situations and that my technical skills are improved (Student 1).

[...] Many students in my class also take part in extracurricular activities such as joining the English clubs or participating in Vietnam-Japan festivals (Student 3).

One of the students acknowledged the importance of EMI in providing students with rich and reliable sources of information. In other words, materials which are not available in Vietnamese are fully exploited thanks to EMI.

It's the ability to read materials written in English. Moreover, I have opportunities to get access to new kinds of exercises which can't be found in textbooks or materials written in Vietnamese. My reading skills are also enhanced when I read English materials. I used to find every piece of information on Google. Now I realize that the information can be unreliable. Now I know exactly where to find information I need (Student 5).

Five out of six interviewees mentioned learning opportunities as an advantage offered by EMI lessons:

\section{[...] learning through English gets me familiar with it over time (Student 2).}

Compared to students in general classes, students in this program will probably gain more technical terms. Words that sound familiar in Vietnamese like "thị truòng" [market] or "thị phần" [market share] are hard to be 
translated into English. But when I attend this class, I find it easy to associate an English word with the thing it refers to. [...] (Student 3).

My listening skills are improved, and I learn more specialized terms and vocabulary items. These can't be found in modules in basic English (Student 4).

[...] My reading skills are also enhanced when I read English materials. [...] (Student 5).

Most of the materials are in English, so my English competence is enhanced. I don't know much about other programs, but I think teachers tend to put a heavy workload on us, meaning that we have to try harder. This in turn develops our self-study skills (Student 6).

As revealed from the interviews, the students' language skills, namely listening and reading skills, are upgraded. However, speaking and writing skills were not mentioned by any of the interviewees. This outcome is in line with the findings from the questionnaire. Obviously, in EMI classrooms under survey, the four language skills are not developed equally. Reception skills, namely listening and reading, seem to be sharpened much more than production skills (speaking and writing). Additionally, vocabulary in general and terminology in particular plays an important role in students' learning process. Especially, a student majoring in Information Technology believed that he could develop self-study skills due to the huge workloads he had to cope with. This perspective may come from the characteristics of the major.

\subsection{Drawbacks of EMI Lessons as Perceived by Students}

With regard to difficulties in comprehending lectures, the mean value of items is 3.26 , meaning that EMI classrooms do bring such challenges.

Table 5. Difficulties in comprehending lectures

\begin{tabular}{llll}
\hline Item & $\begin{array}{l}\text { Agree } \\
(\%)\end{array}$ & $\begin{array}{l}\text { Disagree } \\
(\%)\end{array}$ & $\begin{array}{l}\text { Neutral } \\
(\%)\end{array}$ \\
\hline $\begin{array}{l}\text { I have difficulty in understanding new vocabulary, terminology and } \\
\text { science concepts provided in the lectures. }\end{array}$ & 51.5 & 12.5 & 36 \\
$\begin{array}{l}\text { I have difficulty in understanding the content of the lectures taught in } \\
\text { English. }\end{array}$ & 44.9 & 10.3 & 44.9 \\
$\begin{array}{l}\text { I have difficulty in taking notes during English lectures because of the } \\
\text { lecturer's pronunciation and speed. }\end{array}$ & 39 & 21.3 & 39.7 \\
$\begin{array}{l}\text { I have difficulty in understanding lecturers' instructions and explanations } \\
\text { in English. }\end{array}$ & 38.2 & 17.6 & 44.1 \\
$\begin{array}{l}\text { I acquire limited knowledge content because of low proficiency in } \\
\text { English listening skills. }\end{array}$ & 30.8 & 32.4 & 36.8 \\
\hline
\end{tabular}

Noticeably, the greatest percentage of the students perceived that they have difficulty in understanding new vocabulary, terminology and science concepts provided in the lectures $(51.5 \%)$. Besides, approximately half of the students, namely $44.9 \%$, agreed on the statement "I have difficulty in understanding the content of the lectures taught in English". The two item which got quite similar percentage of agreement are (1) I have difficulty in understanding lecturers' instructions and explanations in English; and (2) I have difficulty in taking notes during English lectures because of the lecturer's pronunciation and speed, with $38.2 \%$ and $39 \%$, respectively. Nearly one-third assumed that they acquire limited knowledge content because of low proficiency in English listening skills (30.8\%).

It can be concluded that around one-third of the students regard understanding the lectures delivered in English as a difficulty. In particular, understanding new vocabulary, terminology and science concepts and comprehending the lecture content pose the most challenges.

In terms of difficulties in comprehending textbooks/course materials, the mean value is 3.38 , which suggests that the students expressed negative attitudes towards EMI lessons in this respect. 
Table 6. Difficulties in understanding textbooks and course materials

\begin{tabular}{llll}
\hline Item & $\begin{array}{l}\text { Agree } \\
(\%)\end{array}$ & $\begin{array}{l}\text { Disagree } \\
(\%)\end{array}$ & $\begin{array}{l}\text { Neutral } \\
(\%)\end{array}$ \\
\hline $\begin{array}{l}\text { It takes me a lot of time to look up new words and terms in a dictionary } \\
\text { when I read textbooks. }\end{array}$ & 56.6 & 15.4 & 27.9 \\
$\begin{array}{l}\text { It takes me a lot of time to understand the language first and then grasp } \\
\text { the content. }\end{array}$ & 47.1 & 16.9 & 36 \\
$\begin{array}{l}\text { I have difficulty in understanding textbooks and course materials written } \\
\text { in English due to limited vocabulary. }\end{array}$ & 45.6 & 17.6 & 36.8 \\
\hline
\end{tabular}

The greatest proportion of agreement went to the statement "It takes me a lot of time to look up new words and terms in a dictionary when I read textbooks", at $56.6 \%$. Additionally, $47.1 \%$ of the students reported that they have to spend a lot of time understanding the language first and then grasping the content. $45.6 \%$ of them also admitted that they have difficulty in understanding textbooks and course materials written in English due to their limited vocabulary.

EMI students also reported drawbacks posed by EMI lessons when they take tests and exams (see Table 7). The mean value for this cluster is 3.37 .

Table 7. Difficulties in tests and exams

\begin{tabular}{llll}
\hline Item & $\begin{array}{l}\text { Agree } \\
(\%)\end{array}$ & $\begin{array}{l}\text { Disagree } \\
(\%)\end{array}$ & $\begin{array}{l}\text { Neutral } \\
\text { (\%) }\end{array}$ \\
\hline $\begin{array}{l}\text { A lack of command of English prevents me from expressing my thoughts } \\
\text { and ideas more accurately. }\end{array}$ & 53.6 & 15.5 & 30.9 \\
$\begin{array}{l}\text { In examinations, I am unable to write the answers in greater detail } \\
\text { because of limited English vocabulary. }\end{array}$ & 46.3 & 23.5 & 30.1 \\
$\begin{array}{l}\text { I cannot memorize terminology and science concepts well. } \\
\text { I don't really understand the questions posed in tests and exams. }\end{array}$ & 30.1 & 23.5 & 46.3 \\
\hline
\end{tabular}

In detail, 53.6\% of the respondents agreed that a lack of command of English prevents them from expressing their thoughts and ideas more accurately; $46.3 \%$ of them reported they are "unable to write the answers in greater detail because of limited English vocabulary". Almost one-third of the students, namely $30.1 \%$, admitted that they "cannot memorize terminology and science concepts well". However, fortunately, just slightly more than one-quarter, namely $27.2 \%$, believed they "do not really understand the questions posed in tests and exams".

Overall, a lack of English skills, especially vocabulary, prevents students from expressing their ideas, thereby hindering them from writing the answers in great detail. In other words, vocabulary poses the most challenges to students when they sit a test or an exam.

Last, students reported that they had difficulties participating in classroom discussions, with a mean value of 3.06 .

Table 8. Difficulties in participating in classroom discussions

\begin{tabular}{llll}
\hline Item & $\begin{array}{l}\text { Agree } \\
(\%)\end{array}$ & $\begin{array}{l}\text { Disagree } \\
(\%)\end{array}$ & $\begin{array}{l}\text { Neutral } \\
(\%)\end{array}$ \\
\hline $\begin{array}{l}\text { I have difficulty in expressing content knowledge because of my limited } \\
\text { vocabulary. }\end{array}$ & 44.1 & 20.6 & 35.3 \\
$\begin{array}{l}\text { Language barriers discourage discussions and interactions between } \\
\text { lecturers and students. }\end{array}$ & 36 & 30.2 & 33.8 \\
$\begin{array}{l}\text { I cannot communicate effectively with the lecturer or express my ideas } \\
\text { clearly in English. }\end{array}$ & 33 & 20.6 & 46.3 \\
\hline
\end{tabular}


I have difficulty in asking questions in English even I am confused about the lesson content during EMI classes.

I have difficulty in participate in the lecture discussion because I cannot understand the content of the lesson sufficiently to ask and answers questions.

Using English to answer the lecturer's questions is my difficulty.

I do not actively participate in classroom discussions because of limited English speaking ability.
33

$33 \quad 32.4 \quad 34.6$

32.4

22.8

30.1

30.9

39

$28.7 \quad 33.8$

37.5

Interestingly, vocabulary once again causes problems for students when they take part in classroom discussions. More specifically, the highest percentage of agreement, namely $44.1 \%$, went to "I have difficulty in expressing content knowledge because of my limited vocabulary". That "Language barriers discourage discussions and interactions between lecturers and students" was agreed upon by $36 \%$ of the participants. The four statements, including (1) I cannot communicate effectively with the lecturer or express my ideas clearly in English; (2) I have difficulty in participate in the lecture discussion because I cannot understand the content of the lesson sufficiently to ask and answers questions; (3) I have difficulty in asking questions in English even I am confused about the lesson content during EMI classes; and (4) Using English to answer the lecturer's questions is my difficulty, received quite similar proportion of agreement, at 33\%, 32.4\%, 33\% and 30.1\%, respectively. Limited speaking ability was regarded as the cause of students' low participation in classroom discussions by $28.7 \%$ of the respondents.

When being asked about the challenges posed in EMI classrooms, the interviewees shared similar ideas:

There are a great deal of terminology that requires a lot of effort to figure out the meaning, or I have to ask my lecturers for clarifications. Terminology is the greatest challenge to me. [...] (Student 1).

The drawbacks lie in English itself. Sometimes, I cannot follow the lecturers because I haven't acquired specialized terminology. I myself have to try to figure out what those words mean, but it seems that it doesn't work because I find it hard to understand the meaning I have found. The meaning provided by the lecturer is different from what I have found. Therefore, we usually use textbooks written in Vietnamese (Student 2).

I think the biggest problem is learning the content of the lectures through English. Acquiring knowledge of subjects focusing on laws, Law in International Trade for example, is quite difficult. In fact, every country has its own laws. Studying laws through English is incomprehensible. I just cannot gain deeper insights into what I have learned. I can't even understand law books written in Vietnamese, let alone ones written in English (Student 3).

While the disadvantages above rooted mainly from students' lack of vocabulary, the ones listed below revealed that students' low and different levels of English proficiency are the main causes for their difficulties.

Perhaps, communicating is the most difficult, especially communicating with the lecturers. I sometimes speak English, sometimes speak Vietnamese to my friends (Student 4).

Lecturers use PowerPoint slides written in English. it is hard to grasp the content because there are unfamiliar vocabulary items. But after a few weeks, if I understand the way a material utilizes vocabulary, I can understand that material as well as lecturers' PowerPoint slides (Student 5).

I think I, as well as my friends, can't grasp the content of the lectures sufficiently. Students' English proficiency varies. When lecturers deliver lessons, some students can understand them, while others don't. Students with good English competence can understand about $70 \%$ of the lessons. Others with low command of English can grasp only about $40 \%$ (Student 6).

In short, students in EMI classes face various types of difficulties.

\section{Discussion}

\subsection{Students' Perceptions of Advantages Offered by EMI Lessons}

As presented in Table 1, just over half of the respondents in the survey agreed that EMI brings them cognitive advantages. In the interviews, the two students who mentioned cognitive advantages major in International Business. That is, no students from College of Information and Communication Technology discuss cognitive advantages. This is interpretable. The reason lies in the characteristics of each major. As regards International Business (IB), students in this program have to attend many courses on social skills, such as Communication Skills, Problem Solving Skills and Critical Thinking skills, Negotiation Skills, Response Skills at Job Market and 
so on (as is observed from the curriculum of this program). Whether they want it or not, they have to develop these ones if they want to perform well in class for the time being or find a well-paid job in the future. Turning to students who major in Information Technology, they spend most of their time working with computers. Therefore, it is understandable if they are not so outgoing as their counterparts, who study economics. However, it is unfair to say that EMI has nothing to do with their friendliness. IT (Information Technology) students usually work in teams. That is, they also develop necessary skills, including negotiation skills, team-work skills, strategic planning skills and organization skills; and for some reason they feel that these skills do not deserve mention.

Regarding resource availability, approximately one-third of the students in the survey agreed that attending an EMI class enables them to find sources of information written in English in general and materials for their major in particular. In the interviews, this was also mentioned by a student studying IT. Such findings are in line with those in previous studies (for example, Alhamami, 2015; Başibek, Dolmac1, Cengiz, Bür, Dilek, \& Kara, 2014; Probyn, 2005; Zare-ee \& Gholami, 2013).

Most of the students, both in the survey and in the interviews, believe that EMI lessons give them excellent chances to enhance their language skills. However, it should be noticed that there is a marked discrepancy in the level of enhancement between reception skills (listening and reading) and production skills (speaking and writing). In terms of listening skills, $60 \%$ of the curriculum is taught through English, meaning that the students have to be accustomed to the lecturers' speed and pronunciation so that they can follow the lessons and ensure that they do not miss any important points. On the basis of reading, a failure at reading and digesting information in the course books may lead to poor performance. Nevertheless, there is a noticeable difference between the habit of reading of IB students and that of IT students. Specifically, IB students prefer reading books in two languages to reading only English books. This is because they need to know what key terms mean in both languages so that they can apply them in their work after graduation, whether they work in their home nation or overseas. IT students experience reading in a different way. Many technical terms in the field make no sense to the reader when they are translated into Vietnamese. Thus, it is better for IT students to use those terms in English language. This is easier for them to follow procedures or instructions given in English. Concerning speaking and writing skills, these ones are still improved during EMI classes. Nonetheless, the level of enhancement is not significant. Usually, students' passive learning style or a lack of vocabulary prevents them from exchanging ideas. Moreover, in EMI classrooms, while ideas or initiatives should be shared in English language, students tend to immediately switch to their mother tongue if they cannot express themselves in English. This practice may undermine students' speaking skills. Similarly, writing skills are not upgraded much due to a lack of exposure to writing. IT students are familiar to code and computer programs, not essays. Assignments in IB classes usually do not require too much effort in writing.

General and specialized vocabulary size of the students is believed to be enhanced greatly. This is accordance with the findings from a study conducted by Tatzl (2011).

A great number of students in the survey agree that EMI prepares them a brighter future with career prospects and studying opportunities. This finding is supported by Tamtam et al. (2012). In this "global village", bilingualism is considered a plus when a person looks for a job in the competitive job market. Because English is an international language, it can be a requirement for almost every job in the future. Therefore, EMI programs are expected to fulfill the students' expectations. Students seem to appreciate English being integrated into a study program.

\subsection{Students' Perceptions of Disadvantages Posed by EMI Lessons}

As regards the difficulties in comprehending the lectures, approximately half of the students responding to the questionnaire acknowledged that they face challenges in understanding new vocabulary items, terminology and science concepts. In addition, results from the interviews revealed similar thoughts. Limited knowledge of vocabulary and low listening competence may lead to a failure at catching lecturers' explanations or instructions and taking notes, which in turn causes gaps in students' content knowledge. This is in line with the findings of several previous researchers, including Chang (2010), Huang (2012), Kagwesage (2012) and Le (2015).

Turning to the challenges the students faced when they read textbooks or course materials written in English, the greatest number of students regarded reading English textbooks the greatest challenge. This finding is accordance with the findings from a study conducted by Chang (2010) and Al-Bakri (2013). Vocabulary was the most frequently reported as the major source of difficulty. Therefore, it is not surprising to find that students have to use dictionaries or other supporting devices or tools to discover the meanings of words first and then translate them into their mother tongue and finally grasp the content. This is extremely time-consuming and proves to be 
ineffective and inefficient. The outcomes from the interviews also suggested that academic vocabulary items used in textbooks or course materials for the two majors under survey (International Business and Information Technology) are quite hard to be translated into Vietnamese. The meanings in Vietnamese may be incomprehensible or make no sense. Some of the students interviewed reported that it was even hard for students majoring in English Studies to translate those words into Vietnamese.

Concerning difficulties in taking tests and exams, the number of students admitting that they do not understand the questions posed in the tests is not very large, which is in contrast with the research outcomes by Al-Bakri (2013) and Sivaramana (2014). However, a great number of students assert that they cannot express their thoughts or ideas accurately because of their lack of command of English skills, especially limited vocabulary. Similar findings can be found in a study conducted in Can Tho University by Le (2015). It can be concluded that students understand the questions, yet their body of vocabulary and a failure at memorizing academic words and terminology prevent them from performing well in exams.

Finally, the results from the questionnaire suggest that around one-third of the students agree that they encounter certain difficulties in taking part in classroom discussions. Nearly $45 \%$ of the respondents considered their limited vocabulary as an obstacle to expressing their content knowledge, asking and answering questions and interacting well with their lecturers or peers. Students are hesitant to ask questions even when they do not understand the content delivered to them. The reason for this may lie in the fact that they are afraid to make mistakes. One more time, the notion that students with poor English language competence hesitate to participate in in-class discussions is supported by the findings from many previous studies by Doiz, Lasagabaster and Sierra (2011), Flowerdew, Li and Miller (1998), Al-Bakri (2013) and Ibrahim (2001).

Overall, the students involving in the present study have experienced a lot of drawbacks of EMI lessons. Among those challenges, comprehending textbooks and course materials written in English appears to be the most significant. Whatever difficulties the students face, knowledge of vocabulary is the major cause. Moreover, English proficiency plays a crucial role in determining students' performance in their learning process.

The findings of the current study provide useful information on the strengths and weaknesses perceived by the students of the EMI programs at the university being researched. The authorities of the programs may want to reconsider the way EMI programs are being conducted to maximize its strengths and minimize its weaknesses.

\section{Conclusion}

This study seeks to discover the advantages and disadvantages of studying specialized subjects as perceived by students of high-quality training programs. The findings from quantitative and qualitative data analysis suggest that students following high-quality study programs think positively about the benefits offered by EMI lessons in terms of resource availability, enhanced English skills and especially job prospects in the future. However, they have also experienced drastic challenges which are primarily caused by their low English competence and insufficient knowledge of vocabulary (both general and academic). Obviously, English proficiency and vocabulary size are considered as the key to accomplishments in EMI classrooms.

It is recommended that further studies be conducted on a larger scale, with a variety of research instruments being combined to gain deeper insights into the nature of EMI. For example, the subjects for further research can be EMI students who are in their second, third and fourth year. This may help researchers to capture an overall view of the effectiveness of EMI programs and to determine whether EMI can enhance students' English proficiency and widen their content knowledge over time. In addition, content teachers' perceptions of EMI in high-quality training programs should also be carefully considered. Additionally, their perceptions of pedagogical skills needed in EMI classrooms are also a direction for further research.

\section{References}

Al-Bakri, S. (2013). Problematizing English medium instruction in Oman. International Journal of Bilingual and Multilingual Teachers of English, 1(2), 55-69. https://doi.org/10.12785/ijbmte/010203

Al-Jarf, R. (2004). College Students' Attitudes towards Using English and Arabic as a Medium of Instruction at the University Level. World Arabic Translator's Association. https://doi.org/10.4324/9781315618623-4

Al-Sultan, A. (2009). English as medium of instruction. Arab News. Retrieved from http://www.arabnews.com/ node/325859

Alhamami, M. (2015). Teaching science subjects in Arabic: Arab university scientists' perspectives. Language Learning in Higher Education, 5(1), 105-123. https://doi.org/10.1515/cercles-2015-0006

Ammon, U., \& McConnell, G. (2002). English as an academic language in Europe: A survey of its use in 
teaching (Duisburger Arbeiten zur Sprach- und Kulturwissenschaft 48). Bern: Peter Lang.

Baker, C., \& Jones, S. P. (Eds.). (1998). Encyclopedia of bilingualism and bilingual education. Multilingual Matters.

Başıbek, N., Dolmacı, M., Cengiz, B. C., Bür, B., Dilek, Y., \& Kara, B. (2014). Lecturers' perceptions of English medium instruction at engineering departments of higher education: A study on partial English medium instruction at some state universities in Turkey. Procedia-Social and Behavioral Sciences, 116, 1819-1825. https://doi.org/10.1016/j.sbspro.2014.01.477

Bialystok, E. (1987). Influences of bilingualism on metalinguistic development. Interlanguage Studies Bulletin (Utrecht), 3(2), 154-166. https://doi.org/10.1177/026765838700300205

Chang, Y. Y. (2010). English-medium instruction for subject courses in tertiary education: Reactions from Taiwanese undergraduate students. Taiwan International ESP Journal, 2(1), 53-82.

Crystal, D. (2003). English as a global language (2nd ed.). Cambridge: Cambridge University Press. https://doi.org/10.1017/CBO9780511486999

Dearden, J. (2014). English as a medium of instruction-a growing global phenomenon. British Council.

Doiz, A., Lasagabaster, D., \& Sierra, J. M. (Eds.). (2012). English-Medium instruction at universities: Global challenges. Bristol: Multilingual Matters. https://doi.org/10.21832/9781847698162

Flowerdew, J., \& Miller, L. (1992). Student perceptions, problems and strategies in second language lecture comprehension. RELC Journal, 23(2), 60-80. https://doi.org/10.1177/003368829202300205

Galloway, N. (2017, September 14). How effective is English as a medium of instruction (EMI)? Retrieved from https://www.britishcouncil.org/voices-magazine/how-effective-english-medium-instruction-emi

Hu, G. W. (2007). The juggernaut of Chinese-English bilingual education. In A. W. Feng (Ed.), Bilingual education in China: Practices, policies and concepts (pp. 94-126). Clevedon, UK: Multilingual Matters. https://doi.org/10.21832/9781853599934-009

Huang, Y. P. (2009). English-only instruction in post-secondary education in Taiwan: Voices from students. Hwa Kang Journal of English Language \& Literature, 15, 145-157.

Huang, Y. P. (2012). Design and implementation of English-medium courses in higher education in Taiwan: A qualitative case study. English Teaching \& Learning, 36(1), 1-51.

Ibrahim, J. (2004). The implementation of EMI (English medium instruction) in Indonesian universities: Its opportunities, its threats, its problems, and its possible solutions. $k @$ ta lama, 3(2), 121-138.

Kagwesage, A. M. (2012). Higher Education Students' Reflections on Learning in Times of Academic Language Shift. International Journal for the Scholarship of Teaching and Learning, 6(2), 1-14. https://doi.org/10. 20429/ijsotl.2012.060218

Keuk, C. N., \& Tith, M. (2013). The enactment of English-medium instruction (EMI) undergraduate program in Cambodia: Students' voices. International Journal of Innovation in English Language Teaching and Research, 2(2), 159-242.

Le, T. D. L. (2015). Content lecturers' and students' challenges in EMI classrooms: A case study at a university in the Mekong Delta. Unpublished Master's thesis. Can Tho University.

Lei, J., \& Hu, G. (2014). Is English-medium instruction effective in improving Chinese undergraduate students' English competence? International Review of Applied Linguistics in Language Teaching, 52(2), 99-126. https://doi.org/10.1515/iral-2014-0005

Madhavan, D., \& McDonald, J. (2014). Webinar: English as Medium of Instruction (EMI): Philosophies and Policies.

Marsh, D., \& Laitinen, J. (2005). Medium of instruction in European higher education: Summary of research outcomes of European Network for language learning amongst undergraduates (ENLU) Task Group 4. Jyvaskyla: Uni COM, University of Jyvaskyla.

MOET. (2008). Đề án đào tạo theo chưong trình tiên tiến tại một số truờng đại học của Việt Nam giai đoạn 2008-2015 (Project document for implementing Advanced programs in some Vietnamese universities in the period 2008-2015).

Nguyen, A. T. (2009). The internationalization of higher education in Vietnam: National policies and 
institutional implementation at Vietnam National University, Hanoi. Waseda University Global COE Program, Global institute for Asian Regional Integration.

Nguyen, H. T., Walkinshaw, I., \& Pham, H. H. (2017). EMI programs in a Vietnamese university: Language, pedagogy and policy issues. English Medium Instruction in Higher Education in Asia-Pacific (pp. 37-52). Springer, Cham. https://doi.org/10.1007/978-3-319-51976-0_3

Pan, J. Z. (2007). Facts and considerations about bilingual education in Chinese universities. In A.W. Feng (Ed.), Bilingual education in China: Practices, policies and concepts (pp. 200-215). Clevedon, UK: Multilingual Matters.

Probyn, M. J. (2005). Learning science through two languages in South Africa. Proceedings of the 4th international symposium on bilingualism. Somerville: Cascadilla Press. Retrieved from http://www.lingref.com/isb/4/145ISB4.PDF

Rundall, R., \& Hernandez, F. (1986). Asian teachers: A new dimension. The Clearing House, 60(2), 91-92. https://doi.org/10.1080/00098655.1986.9959293

Senapati, P., Patnaik, N., \& Dash, M. (2012). Role of medium of instruction on the development of cognitive processes. Journal of Education and Practice, 3(2), 58-66.

Sivaramana, I., Al Balushib, A., \& Rao, D. H. (2014). Understanding Omani students'(University) English language problems. International Journal of Sciences: Basic and Applied Research (IJSBAR), 13(1), 28-35.

Swain, M., \& Johnson, R. K. (1997). Immersion education. In W. R. K. Johnson, \& M. Swain (Eds.) A Category Within Bilingual Education (pp. 1-18). Immersion Education: International Perspectives. Cambridge: CUP. https://doi.org/10.1017/CBO9781139524667.003

Tamtam, A. G., Gallagher, F., Olabi, A. G., \& Naher, S. (2012). A comparative study of the implementation of EMI in Europe, Asia and Africa. Procedia-Social and Behavioral Sciences, 47, 1417-1425. https://doi.org/10.1016/j.sbspro.2012.06.836

Tatzl, D. (2011). English-medium masters' programmes at an Austrian university of applied sciences: Attitudes, experiences and challenges. Journal of English for Academic Purposes, 10(4), 252-270. https://doi.org/10. 1016/j.jeap.2011.08.003

Tong, F., \& Shi, Q. (2012). Chinese-English bilingual education in China: A case study of college science majors International Journal of Bilingual Education and Bilingualism, 15(2), 165-182. https://oi.org/10.1080/ 13670050.2011.607921

Vu, T. T. N., \& Burns, A. (2014). English as a medium of instruction: Challenges for Vietnamese tertiary lecturers. The journal of Asia TEFL, 11(3), 1-31.

Wright, S. (2002). Language education and foreign relations in Vietnam. Language policies in education: Critical issues, 225-244.

Zare-ee, A., \& Gholami, K. (2013). Academic justifications for preferring English as a medium of instruction by Iranian university teachers. Proceedings of the Global Summit on Education, 426431. https://doi.org/10.31235/osf.io/jt3ux

Zhang, Y. X. (2002). Jiaqiang shiyongxing yingyu jiaoxue tigao daoxuesheng yingyu zonghe nengli [Strengthening communication-based English language teaching and raising university students' comprehensive English competence]. Zhongguo Gaodeng Jiaoyu, 8, 3-6.

\section{Copyrights}

Copyright for this article is retained by the author(s), with first publication rights granted to the journal.

This is an open-access article distributed under the terms and conditions of the Creative Commons Attribution license (http://creativecommons.org/licenses/by/4.0/). 